\title{
Avaliação da união por Ponto de chapas finas de Aluminio AA3003 via Processo de Soldagem por Atrito e Mistura (FSW)
}

\section{Laura S. Fernandes, Rodrigo J. Contieri.}

\section{Resumo}

Este trabalho é resultado da avaliação do processo de soldagem por ponto por atrito e mistura (Friction Stir Welding, FSW). Através de diferentes condições de processo, foi encontrada a melhor condição de processamento de modo que as propriedades mecânicas e aspectos microestruturais fossem otimizados. Velocidades de rotação baixas, proximas de 1000 RPM geraram uniões com pouca consolidação mecânica. No entanto, quando aplicado rotações superiores a 1800 RPM, o aspecto de contato mecânico foi mais efetivo e consolidao, gerando em consequência, os melhores resultados de limite de escoamento e de limite de resistência mecânica a tração.

Palavras-chave:

Liga de alumínio, Friction Stir Processing - FSW, Soldagem.

\section{Introdução}

O processo de soldagem por atrito e mistura, mas conhecido por FSW (Friction Stir Welding), diferentemente dos processos convencionais de soldagem em que existe a presença de uma fase líquida, é realizado no estado sólido, e produz soldas pela rotação ou movimento relativo de duas peças sob forças compressivas, produzindo calor e deformando plasticamente o material na superfície de atrito. Ao utilizar esta técnica se diminui grandemente a perda de propriedades geralmente sofrida pela parte fundida da matriz soldada, melhorando seu processamento e garantindo melhores resultados ${ }^{1}$.

Comparado a outros processos de soldagem, o FSW tem a vantagem de consumir menos energia, não emitir gases e não consumir materiais, como eletrodos, material de preenchimento e gases para controle de atmosfera. A adoção do FSW tem aumentado uma vez que é uma técnica comprovada quanto a sua eficiência e economia. O objetivo deste trabalho é investigar a união de duas chapas de $1 \mathrm{~mm}$ de espessura da liga de alumínio AA3003 através deste processo e a avaliar os melhores parâmetros, sendo eles: rotação da ferramenta e tempo de processamento.

\section{Resultados e Discussões}

Foram realizadas 12 soldas ponto pelo processo de soldagem por atrito de modo a unir duas chapas da liga de alumínio AA3003 com $1 \mathrm{~mm}$ de espessura cada. Os parâmetros variados foram: Rotação da Ferramenta, entre 1000 e 2000 RPM, e o tempo de processamento, entre 5 a 10 segundos.

As amostras foram então cortadas em seu centro, de modo que se pudesse analisar o ponto de união entre as chapas. Durante este processo três das amostras foram descartadas por análise visual, visto que a solda não resistiu ao corte e as duas chapas se desprenderam. As amostras restantes foram embutidas em resina, lixadas e polidas, como mostra a Figura 1. Do lado esquerdo, de cima para baixo, amostras número $3,4,5,6$ e 7 , respectivamente. Do lado direito, de cima para baixo, amostras número 9,10,11 e 12, respectivamente.

A Tabela 1 mostra os parâmetros utilizados em cada uma das amostras, além de uma avaliação final feita com a ajuda do microscópio. Em certos parâmetros foi possível notar a presença de pequenas trincas e pouco contato na região da solda, o que nos leva a acreditar que possuam qualidade inferior.

Figura 1. Amostras embutidas, lixadas e polidas.

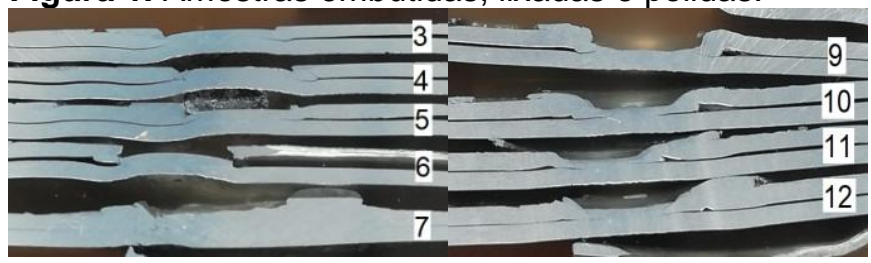

Tabela 1. Parâmetros das amostras e avaliação.

\begin{tabular}{|c|l|c|c|}
\hline Amostra & RPM & Tempo & Avaliação \\
\hline 1 & 1000 & $5 \mathrm{~s}$ & Descartada \\
\hline 2 & 1200 & $5 \mathrm{~s}$ & Descartada \\
\hline 3 & 1400 & $5 \mathrm{~s}$ & Bom contato \\
\hline 4 & 1600 & $5 \mathrm{~s}$ & Presença de trincas \\
\hline 5 & 1800 & $5 \mathrm{~s}$ & Bom contato \\
\hline 6 & 2000 & $5 \mathrm{~s}$ & Presença de quebra \\
\hline 7 & 1000 & $10 \mathrm{~s}$ & Melhor contato \\
\hline 8 & 1200 & $10 \mathrm{~s}$ & Descartada \\
\hline 9 & 1400 & $10 \mathrm{~s}$ & Presença de quebra \\
\hline 10 & 1600 & $10 \mathrm{~s}$ & Pouco contato \\
\hline 11 & 1800 & $10 \mathrm{~s}$ & Pouco contato \\
\hline 12 & 2000 & $10 \mathrm{~s}$ & Bom contato \\
\hline \multicolumn{4}{|r}{} \\
\hline
\end{tabular}

\section{Conclusões}

Através da avaliação pode-se perceber os melhores parâmetros avaliados foram para condições de processamento que gerassem aporte térmicos mais altos, ou seja, alta velocidade de rotação e maior tempo de processo. No entanto, para os resultados preliminares foi observada uma certa aleatoriedade sobre os resultados, podendo ser relacionada ao problema de fixação do material, já que com a melhora da fixação, melhores uniões forma obtidas.

${ }^{1}$ Sattari, S.; Bisadi, H.; Sajed, M.. Mechanical Properties and Temperature Distributions of Thin Friction Stir Welded Sheets of AA5083. International Journal Of Mechanics And Applications, [s.1.], v. 2, n. 1, p.1-6, 31 ago. 2012. Scientific and Academic Publishing.

2 Coelho, R.S. et al. Friction-stir dissimilar welding of aluminium alloy to high strength steels: Mechanical properties and their relation to microstructure. Materials Science \& Engineering A 556. 2012. 175-183. 